\title{
Allelopathic and competitive interactions between native and alien plants
}

\author{
Ling Yuan · Jun-Min Li $\cdot$ Fei-Hai Yu $\cdot$ Ayub M. O. Oduor $\cdot$ Mark van Kleunen $\mathbb{C}$
}

Received: 24 January 2021 / Accepted: 1 May 2021/Published online: 10 May 2021

(C) The Author(s) 2021

\begin{abstract}
The novel-weapons and homeland-security hypotheses are based on the idea that aliens and natives are not adapted to each other's allelochemicals as they did not co-evolve. However, as only a few studies have tested this, it remains unclear how important co-evolutionary history is in determining the strength of allelopathic interactions between aliens and natives. Here, we tested for potential pairwise allelopathic effects on each other of five alien and five native herbaceous species in China. We did a germination experiment and a competition experiment. In the germination experiment, we tested whether aqueous extracts of the ten study species had allelopathic effects on each other's seed germination. In the competition experiment, we tested whether the alien
\end{abstract}

Supplementary Information The online version contains supplementary material available at https://doi.org/10.1007/ s10530-021-02565-w.

L. Yuan · J.-M. Li · F.-H. Yu •

A. M. O. Oduor · M. van Kleunen

Zhejiang Provincial Key Laboratory of Plant Evolutionary

Ecology and Conservation, Taizhou University,

Taizhou 318000, China

A. M. O. Oduor

Department of Applied Biology, Technical University of Kenya, P.O. Box 52428-00200, Nairobi, Kenya

M. van Kleunen $(\square)$

Ecology, Department of Biology, University of Konstanz, 78464 Konstanz, Germany

e-mail: mark.vankleunen@uni-konstanz.de and native species differed in their competitive effects and responses, and whether these were changed by the presence of activated carbon-a presumed allelopathy neutralizer- in the soil. Plant extracts had negative allelopathic effects on seed germination. This was particularly the case for extracts from the native species. Moreover, aqueous extracts had slightly stronger negative effects on germination of the aliens than on germination of the natives. In the competition experiment, on the other hand, the natives suffered more from competition than the alien species did, but we could not relate this to allelopathy. Alien plants had negative competitive and allelopathic effects on native plants, but the reverse was also true. These aliennative interactions, however, were not consistently stronger or weaker than native-native or alien-alien interactions.

Keywords Allelochemicals - Indigenous plants · Exotic plants $\cdot$ Seedling emergence $\cdot$ Interference competition

\section{Introduction}

With increasing globalization, thousands of plant species have been introduced from their native areas into foreign lands. Although many of those alien plant species are found in cultivation only (van Kleunen 
et al. 2018a), over 13,000 alien species worldwide have established persistent wild populations (i.e., have become naturalized; van Kleunen et al. 2015). Some of those naturalized plants are considered invasive, as they spread rapidly (Richardson et al. 2000), and can have negative ecological (Vilà et al. 2011) and socioeconomic impacts (e.g. Schaffner et al. 2020). Hence, it is important to identify mechanisms that underlie naturalization and invasion success (Sakai et al. 2001; van Kleunen et al. 2018b).

It has frequently been suggested that strong competitors are more likely to become invasive (e.g. Baker 1974). Indeed, empirical studies found evidence that many invasive plants exert stronger competitive effects or are more tolerant to competition than many native ones (Kuebbing and Nuñez 2016; Golivets and Wallin 2018; Zhang and van Kleunen 2019). The high competitiveness of invasive aliens could be due to them having traits, such as high specific leaf area and low root tissue density (Pyšek and Richardson 2007; van Kleunen et al. 2010; Lachaise et al. 2021), which allow them to rapidly take up available resources, and consequently have high intrinsic growth rates (Dawson et al. 2011; Zhang and van Kleunen 2019). However, as already pointed out by Baker (1974), the high competitiveness could also be due to the production of allelochemicals that suppress germination and growth of neighboring plants. This suppression can be due to direct inhibition of the plants or due to inhibition of mutualistic microbes of the plants (e.g. Stinson et al. 2006). Indeed, the novel-weapons hypothesis predicts that some alien plants are successful invaders because they produce allelopathic compounds to which the native plants are not adapted (Callaway and Ridenour 2004). These allelopathic compounds may be released through leaf leachates, root exudates, volatiles and decaying above- and below-ground litter (Callaway and Ridenour 2004; Callaway et al. 2005; Inderjit et al. 2011). Several studies provided support for the novel-weapons hypothesis (e.g. Ridenour and Callaway 2001; Prati and Bossdorf 2004; Abhilasha et al. 2008; GómezAparicio and Canham 2008; Thorpe et al. 2009; Li and Jin 2010; Inderjit et al. 2011; Becerra et al. 2018; Irimia et al. 2019), suggesting that allelopathy can play an important role in the ability of invasive plants to suppress native plants.

If allelochemicals released by alien plants are novel to natives, the reverse should also be true. In other words, alien plant species, irrespective of whether they are invasive or not, may also be susceptible to negative effects of allelochemicals released by native species. This idea was already proposed by Rabotnov (1982), and is now known as the homeland-security hypothesis (Cummings et al. 2012). There is empirical support for the predictions of this hypothesis (Cummings et al. 2012; Christina et al. 2015; Ning et al. 2016; Mignoni et al. 2018; Adomako et al. 2019). For instance, phytochemicals released by the native legume Sesbania virgate reduced germination and seedling growth of the alien invader Leucaena leucocephala in Brazil (Mignoni et al. 2018). However, as only a few studies have tested the homeland-security hypothesis, it remains unclear how common allelopathic effects of native plants on alien plants are. Moreover, it is not known whether these effects are of similar magnitudes as the allelopathic effects of alien plants on native plants, of natives on other natives, and of aliens on other aliens.

Here, we tested for potential pairwise allelopathic effects on each other of five species that are alien and five species that are native to China. As allelopathic effects may act at different stages of a plant's life cycle, we did both a germination experiment and a competition experiment. In the germination experiment, we tested whether aqueous extracts of the ten study species had allelopathic effects on their seed germination. In the competition experiment, we tested whether the alien and native species differed in their competitive effects and responses, and whether these were changed by the presence of activated carbon-a presumed allelopathy neutralizer- in the soil. Specifically, we addressed the following questions: (1) Do the effects of aqueous plant extracts on germination and the germination responses to the aqueous extracts differ between the native and alien species? (2) Do the native and alien species differ in their competitive effects and responses to competition, and are the competitive interactions mediated by allelopathy?

\section{Materials and methods}

\section{Study species}

We obtained seeds of five species that are native and five species that are alien to eastern China. All ten species are herbaceous. The seeds were bulk collected 
from fields in Taizhou (Zhejiang province, China) or obtained as bulk seed samples from commercial seed companies (Table 1). The field collected seeds were from c. five individuals per species, and for the other species the number of individuals is unknown. The 10 species were selected on the basis that they are herbaceous and co-occur across a wide range of habitats in eastern China (Zhang and Ding 1993). To avoid a bias towards including species with unusually strong allelopathic effects, we did not consider a priori information on phytotoxic or allelopathic effects when we selected our study species. However, later literature searches revealed that allelopathic effects have been reported for the alien species Crotalaria pallida (Ohdan et al. 1995; Zhao et al. 2019) and Trifolium repens (Wang et al. 2012; Yu et al. 2013), and for the native species Grycyrrhiza uralensis (Yan et al. 2020). A criterion for selecting the five alien species was that they are all fully naturalized in China. All five aliens are naturalized in more than 18 of the 34 Chinese provinces (including municipalities and autonomous regions) (Yan et al. 2019), and have been classified as a locally invasive plant, common invasive plant or serious invasive plant (Yan et al. 2014) (Table 1).

\section{Germination experiment}

To test the effects of aqueous extracts of the 10 study species on seed germination of themselves and each other, we first grew plants for the production of the extracts. On 4 January 2018, 100 or more seeds of each of the ten species were sown in plastic trays $(1 \times \mathrm{w} \times$ h: $54 \times 28 \times 5 \mathrm{~cm}$ ) that had been filled with an 1:1 (v:v) mixture of sand and vermiculite (both purchased from Xiaoxuan Horticulture, Hebei province, China). The trays were then placed in a phytochamber (daytime temperature: $18-21{ }^{\circ} \mathrm{C}$, night-time temperature: 16-20 ${ }^{\circ} \mathrm{C}$, day length: $14 \mathrm{~h}$, relative humidity: $60 \%$ ). For each species, at least 32 seeds germinated. Two weeks after emergence, 10 of the seedlings of each species were transplanted individually into 1-L plastic pots that had been filled with an 1:1 (v:v) mixture of sand and vermiculite. So, for each species, we had 10 pots, each with one plant. The pots were transferred to a phytochamber with the same conditions as for germination. The seedlings were fertilized once a week for a total of 15 weeks with a Woshibao ${ }^{\circledR}$ liquid fertilizer (N: 50 g/L, P: 30 g/L, K: 50 g/L, Mg: 1.8 g/ L, S: $2.2 \mathrm{~g} / \mathrm{L}$, micronutrients: $0.2 \mathrm{~g} / \mathrm{L}$ ) (purchased from Woshibao Fertilizer Sales Co., Ltd, Lu'an, China), which was diluted 1:200 with distilled water. We watered the plants twice a week ad libitum.

Like the vast majority of allelopathy studies (Zhang et al. 2020), we used plant extracts. To produce aqueous extracts, we harvested five of the ten plants per species after 15 weeks of growth (i.e. on 10 April 2018). We washed the roots to remove the growth medium. We then chopped each plant into $2 \mathrm{~cm}$ pieces, mixed the shoot and root pieces of the five plants per species, and took a random sample of $300 \mathrm{~g}$ from each species. We transferred the sampled plant tissue into a beaker containing $900 \mathrm{~mL}$ of distilled water and let it soak for $24 \mathrm{~h}$ at room temperature. Although in nature, allelopathy can act by inhibition of mutualistic microbes (Stinson et al. 2006), we here focused on possible direct inhibition of germination. Therefore, the extracts were filtered, first through a layer of Whatman No. 1 filter paper, and then-to remove fungal spores- through a $0.8 \mu \mathrm{m}$ filter membrane (25 $\mathrm{mm}$ in diameter) into separate autoclaved Falcon tubes. A fresh filter membrane was used each time. The filtrate was stored at $-20{ }^{\circ} \mathrm{C}$ until use.

To test for allelopathic effects of the aqueous extracts of each of the 10 species on seed germination of the 10 species, we set up a germination experiment at Taizhou University, China. We filled a total of 660 Petri dishes (6 $\mathrm{cm}$ in diameter) with high strength agar gel that contained the aqueous extracts. For this, the frozen plant extracts were thawed in a heating cabinet at $35{ }^{\circ} \mathrm{C}$ for $30 \mathrm{~min}$. They were filtered once more under sterile conditions through $0.8 \mu \mathrm{m}$ filter membranes. Then, for each species, we thoroughly mixed $300 \mathrm{~mL}$ of the filtrate with $600 \mathrm{~mL}$ of warm, liquid agar medium in separate beakers. Finally, $10 \mathrm{~mL}$ of the extract-agar mixture was poured into each Petri dish, after which it cooled down and solidified. As a control treatment, we used agar medium in which we had mixed distilled water instead of plant extract.

On 15 and 16 April 2018, we sowed the seeds. Prior to sowing, the seeds were sterilized for $5 \mathrm{~min}$ in a $5 \%$ sodium hypochlorite solution and rinsed with distilled water. In each Petri dish, we placed 10 seeds of one of the 10 species. The experimental set-up resulted in a total of 660 Petri dishes: 10 plant species $\times 11$ extract types (10 plant-species extracts and 1 control of distilled water) $\times 6$ replicates (see Fig. 1 for all species combinations). We sealed each Petri dish with parafilm to avoid evaporative loss of water. The 660 
Table 1 Information on the ten herbaceous study species

\begin{tabular}{|c|c|c|c|c|c|c|}
\hline Species & Family & $\begin{array}{l}\text { Number of } \\
\text { Chinese } \\
\text { provinces }\end{array}$ & $\begin{array}{l}\text { Status in China } \\
\text { (year of first } \\
\text { record) }\end{array}$ & $\begin{array}{l}\text { Region of } \\
\text { origin }\end{array}$ & Life cycle & Seed source \\
\hline $\begin{array}{l}\text { Amaranthus tricolor } \\
\mathrm{L}\end{array}$ & Amaranthaceae & 34 & Alien-3 (1909) & Tropical Asia & Annual & $\begin{array}{l}\text { Junjie Nursery Stock } \\
\text { Company } \\
\text { (Jiangsu,Suqian) }\end{array}$ \\
\hline $\begin{array}{l}\text { Lepidium virginicum } \\
\mathrm{L}\end{array}$ & Brassicaceae & 33 & Alien-2 (1910) & North America & Annual/biennial & Field in Taizhou \\
\hline Trifolium repens $\mathrm{L}$ & Fabaceae & 31 & Alien-2 (1908) & $\begin{array}{l}\text { Europe, and } \\
\text { parts of Asia } \\
\text { and Africa }\end{array}$ & Perennial & $\begin{array}{l}\text { Junjie Nursery Stock } \\
\text { Company } \\
\text { (Jiangsu, Suqian) }\end{array}$ \\
\hline $\begin{array}{l}\text { Capsella bursa- } \\
\text { pastoris (L.) Medik }\end{array}$ & Brassicaceae & 34 & Alien-4 (1906) & $\begin{array}{l}\text { Europe, and } \\
\text { parts of Asia } \\
\text { and Africa }\end{array}$ & Annual & Field in Taizhou \\
\hline $\begin{array}{l}\text { Crotalaria pallida } \\
\text { Aiton }\end{array}$ & Fabaceae & 19 & Alien-3 (1913) & $\begin{array}{l}\text { Tropical } \\
\text { Africa and } \\
\text { Tropical Asia }\end{array}$ & Perennial & $\begin{array}{l}\text { Junjie Nursery Stock } \\
\text { Company } \\
\text { (Jiangsu, Suqian) }\end{array}$ \\
\hline $\begin{array}{l}\text { Achyranthes } \\
\text { bidentata } \text { Blume }\end{array}$ & Amaranthaceae & 14 & Native & $\begin{array}{l}\text { Eastern and } \\
\text { Tropical Asia }\end{array}$ & Perennial & $\begin{array}{l}\text { Thousand Green } \\
\text { Seed Company } \\
\text { (Jjiangsu,Suqian) }\end{array}$ \\
\hline $\begin{array}{l}\text { Crepidiastrum } \\
\text { sonchifolium } \\
\text { (Maxim.) Pak \& } \\
\text { Kawano }\end{array}$ & Asteraceae & 19 & Native & Eastern Asia & $\begin{array}{l}\text { Annual/ } \\
\text { Biennial }\end{array}$ & $\begin{array}{l}\text { Thousand Green } \\
\text { Seed Company } \\
\text { (Jjiangsu,Suqian) }\end{array}$ \\
\hline $\begin{array}{l}\text { Platycodon } \\
\text { grandiflorus (Jacq.) } \\
\text { A. DC }\end{array}$ & Campanulaceae & 22 & Native & Eastern Asia & Perennial & $\begin{array}{l}\text { Thousand Green } \\
\text { Seed Company } \\
\text { (Jjiangsu,Suqian) }\end{array}$ \\
\hline $\begin{array}{l}\text { Glycyrrhiza uralensis } \\
\text { Fisch }\end{array}$ & Fabaceae & 11 & Native & $\begin{array}{l}\text { Temperate } \\
\text { Asia }\end{array}$ & Perennial & $\begin{array}{l}\text { Thousand Green } \\
\text { Seed Company } \\
\text { (Jjiangsu,Suqian) }\end{array}$ \\
\hline Plantago asiatica $\mathrm{L}$ & Plantaginaceae & 27 & Native & $\begin{array}{l}\text { Eastern and } \\
\text { Tropical Asia }\end{array}$ & $\begin{array}{l}\text { Biennial/ } \\
\text { perennial }\end{array}$ & $\begin{array}{l}\text { Wancao Seed } \\
\text { Industry (Hebei, } \\
\text { Baoding) }\end{array}$ \\
\hline
\end{tabular}

Information on the number of Chinese provinces in which a species occurs is from Yan et al. (2019) for alien species, and from the Flora of China (http://www.efloras.org/flora_page.aspx?flora_id=2) for native species. Information on the alien status and its invasiveness level in China is from Yan et al. (2014): Alien-2 = serious invasive plant (i.e. alien species having obvious impact on the economy or environment), Alien-3 = locally invasive plant (i.e. alien species having local impacts), Alien-4 (i.e. alien species that are common but do not have obvious impacts). Iinformation on the year of first record of alien species is from the Chinese Virtual Herbarium (https://www.cvh.ac.cn/). Information on the region of origin is from POWO (2019). Information on the life cycle is from the Flora of China

Petri dishes were randomly allocated to positions within a phytochamber (day-time temperature: $21^{\circ} \mathrm{C}$, night-time temperature: $16^{\circ} \mathrm{C}$, day length: $15 \mathrm{~h}$, relative humidity: $60 \%$ ). We recorded the number of seeds that had germinated in each Petri dish daily. This allowed us to calculate germination success as the proportion of germinated seeds, and the days to first germination. On 16 July 2018, c. two months after the last seedling had emerged, we stopped the experiment.

\section{Competition experiment}

To test for pairwise competitive interactions between the five native and five alien study species, and whether allelopathy is likely to play a role therein, we conducted a competition experiment factorially crossed with an activated carbon treatment. We first grew seedlings of each species as described above for the germination experiment. Then, on 1-3 September 2018, we transplanted 15-day-old seedlings into 2-L 


\section{(a)}
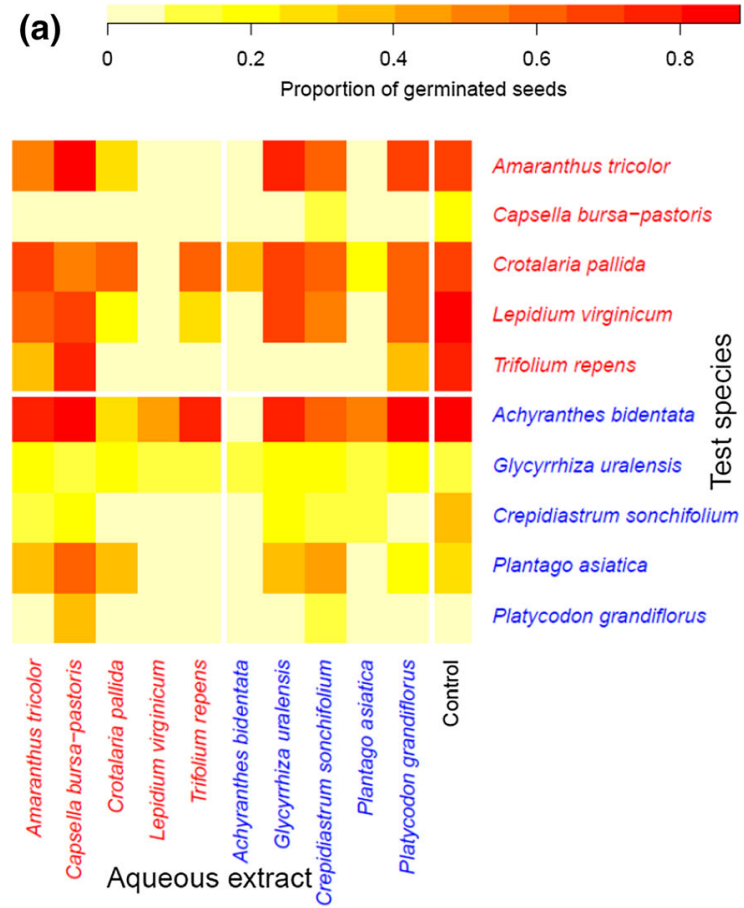

(b)
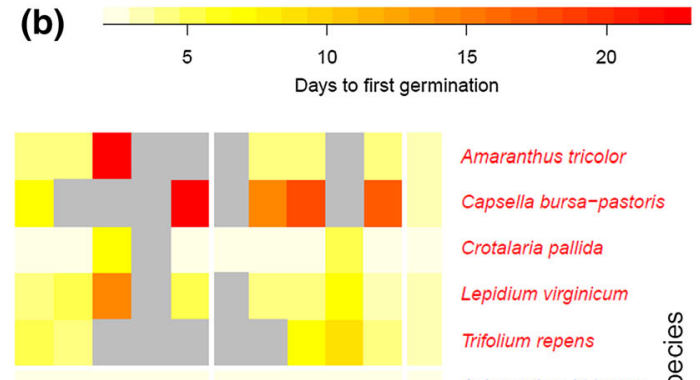

Amaranthus tricolor

Capsella bursa-pastoris

Crotalaria pallida

Lepidium virginicum

Trifolium repens

Achyranthes bidentata

Glycyrrhiza uralensis $\stackrel{\infty}{\mathscr{Q}}$

Crepidiastrum sonchifolium

Plantago asiatica

Platycodon grandiflorus

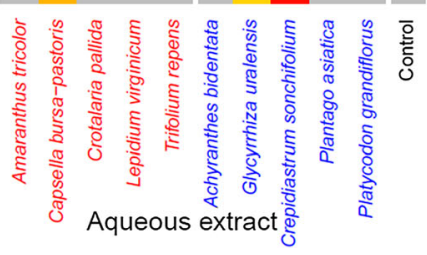

Fig. 1 Heatplots showing the mean (a) proportion of germinated seeds and (b) days to first germination for each combination of a test species and a plant-extract species (or the water control). Alien species are in red, and native species are in blue. Combinations with missing data are indicated in grey pots that had been filled with a $1: 1(\mathrm{v}: \mathrm{v})$ mixture of sand and vermiculite. To provide the plants with sufficient nutrients during the experiment, we mixed $9 \mathrm{~g}$ of Osmocote slow-release fertilizer (N:P: $K=14: 14: 14$ ) into the substrate of each pot. Each of the species was grown in pairwise competition with each of the other species (i.e. with interspecific competition), with itself (i.e. with intraspecific competition) and without competition. Two plants were grown in each pot of the interspecific and intraspecific competition treatments, and one in each pot of the treatment without competition. In the pots with two plants, one was assigned as the target plant and the other as the competitor. So, to avoid problems due to non-independence of plants in the same pot, each plant was either a target or a competitor, not both. To remove or reduce potential allelopathic effects, we crossed the competition treatments with an activated carbon treatment (with or without). Each treatment combination was replicated four times, resulting in 880 pots: 11 levels of competition ( 9 interspecific +1 intraspecific +1 without competition) $\times 2$ levels of activated carbon $\times 10$ species $\times 4$ replicates.

For the treatment with activated carbon, we mixed $40 \mathrm{~mL}$ of activated carbon (CASNO: 7440-44-0, EMD Millipore Corporation, Billerica MA, USA) into each pot prior to transplanting the seedlings. The concentration of activated carbon that we used $(20 \mathrm{~mL} / \mathrm{L})$ was also used in previous studies on allelopathy (e.g. Lau et al. 2008; Weißhuhn and Prati 2009; Ning et al. 2016; Adomako et al. 2019). The 880 pots were randomly allocated to positions on three tables in a greenhouse. The experiment lasted 11 weeks, during which the pots were re-randomized twice (on 27 September and 26 October 2018). The plants were watered regularly $(50 \mathrm{~mL}$ water per pot each time). The minimum and maximum temperatures in the greenhouse were set to 22 and $26^{\circ} \mathrm{C}$, respectively. On 4 November 2018, we scored the survival status of each plant in each pot, and, on 18-20 November 2018, we harvested above-ground biomass of all plants individually. For the plants without competition, we also harvested the below-ground biomass (see Supplementary material), but this was not possible for the plants with competition, because the roots of the two plants could not be disentangled. 
Statistical analyses

All analyses were done in $\mathrm{R}$ version 3.6.1 ( $\mathrm{R}$ Core Team 2019). The proportion of germinated seeds and the number of days to first germination in the germination experiment, as well as survival and above-ground biomass in the competition experiment were analyzed with generalized linear mixed models (GLMMs) using functions of the packages lme4 (Bates et al. 2014) and nlme (Pinheiro et al. 2015).

For the proportion of germinated seeds, we used a binomial error distribution, and, for the number of days until first germination, we used a Poisson error distribution. In both models, we included 'Origin' (alien vs native) of the test species, 'Extract type' (control, self, alien species, native species) and their interaction as fixed terms. We accounted for variation in the response variable among test species and for variation in the effects of the species that served as sources of extracts by including identities of the test and extract species (including the control) as random terms. To test the effects of the individual extract types in more detail, we created three dummy variables to make three planned orthogonal contrasts. First, we tested whether the effects of the aqueous plant extracts differed from the control treatment (i.e. water). Second, among the treatments with aqueous plant extracts, we tested whether the effects of the plant species on itself differed from those of other species. Third, among the aqueous extracts of other plant species, we tested whether the effects of alien species differed from those of native species.

For above-ground biomass in the competition experiment, we used a Gaussian error distribution. In the model, we included 'Activated carbon' (with vs without), 'Origin' (native vs alien) of the test species, 'Competition treatment' (intraspecific competition, interspecific with alien species, interspecific with native species, without competition) and their interactions as fixed terms. We accounted for variation in above-ground biomass among target species and for variation in effects of the species that served as competitors by including them as random terms. To improve normality and homoscedasticity of the residuals, above-ground biomass was cubic transformed, and the varIdent function was used to allow for different variances per test species (Zuur et al. 2009). To test the effects of competition treatment in more detail, we created three dummy variables to make three planned orthogonal contrasts. First, we tested whether the effects of competition differed from the effects of treatment without competition. Second, among the treatments with competition, we tested whether the effects of intraspecific and interspecific competition differed. Third, among the interspecific treatments, we tested whether the effects of alien species differed from those of native species.

In all GLMMs, we assessed the significance of the fixed terms with log-likelihood-ratio tests (Zuur et al. 2009), in which a model with the term of interest was compared to a model without that term. The loglikelihood ratios are approximately $\chi^{2}$-distributed (Zuur et al. 2009).

\section{Results}

Germination experiment

Species varied in their germination success (i.e. proportion of germinated seeds), with the lowest and highest values for the natives Platycodon grandiflorus (4\%) and Achyranthes bidentata (61\%), respectively (Fig. 1a). Germination success also depended on the species used as source for the extract, with the lowest germination on extracts made of the alien Lepidium virginicum (6\%) and the native Achyranthes bidentata $(6 \%)$, and the highest germination on extracts made of the alien Capsella bursa-pastoris (49\%; Fig. 1a).

Averaged across all treatments, the proportion of seeds that germinated did not differ significantly between alien and native test species (Fig. 2a, Table 2). The presence of a plant extract (compared to the water-control treatment) reduced the germination, most strongly for the alien test species and only little for the native test species (Fig. 2a; significant Origin $\times$ [Extract vs control] interaction in Table 2). Seeds, particularly those of alien species treated with extracts of native plants had a slightly, but significantly, stronger germination reduction than seeds treated with extracts of alien plants (Fig. 2a; Table 2). However, germination was overall lowest for seeds treated with extracts of the same species (Fig. 2a; Table 2).

Among the Petri-dishes with germinated seeds, the ones with a low proportion of germinated seeds also germinated later (Pearson's $\mathrm{r}=-0.41, \mathrm{n}=357$, $P<0.001)$. The slowest and fastest germination were 
found for the natives Platycodon grandiflorus (16 days) and Achyranthes bidentata (2 days), respectively (Fig. 1b). The slowest germination was found on extracts made of the alien Crotalaria pallida (10 days), and the fastest germination on extracts made of the alien Amaranthus tricolor (5 days; Fig. 1b).

On average, the alien and native species did not differ in the number of days to first germination (Fig. 2b; Table 2). The presence of plant extracts delayed the germination (significant Extract vs control effect), and this was particularly the case for the alien test species (Fig. 2b; significant Origin $\times$ [Extract vs control] interaction in Table 2). The effect of extracts of the same plant species did not significantly differ from those of other plant species (Fig. 2b; Table 2). Germination of the native test species was delayed slightly more by extracts of other native species than by extracts of alien species, whereas the reverse was true for the alien test species (Fig. 2b; significant Origin $\times$ [Alien vs native] interaction in Table 2).

\section{Competition experiment}

Of the 880 target plants in the competition experiment, 76 had died by the end of the experiment. Survival varied among species, and was reduced by the presence of activated carbon, particularly for the

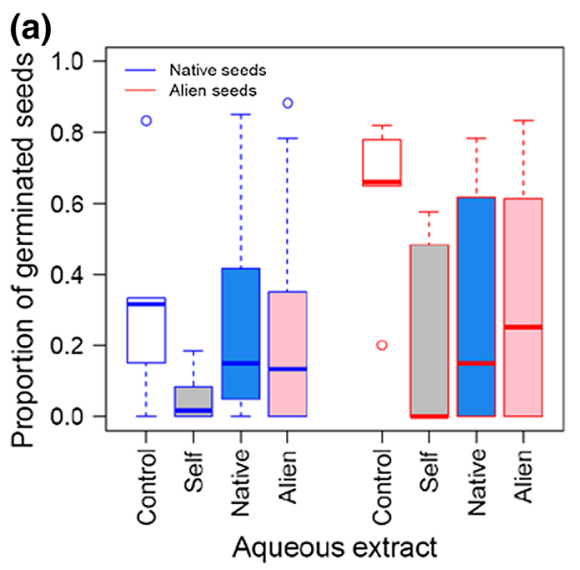

Fig. 2 Boxplots of (a) the proportion of germinated seeds and (b) the number of days to first germination for alien (red box lines) and native species (blue box lines) for the control treatment (white filling of boxes), and treatment with plant extracts of the species itself (grey filling), a native species (light blue filling) and an alien species (light red filling). The boxplots native species (89.3\% survival for native species vs 93.4\% for alien species; Fig. S1; Table S1).

Above-ground biomass varied among species, but on average did not differ between the native and alien species (Figs. 3 and 4; Table 3). Above-ground biomass was significantly reduced by the presence of competition, and also by the presence of activated carbon (Figs. 3 and 4; Table 3). The negative effect of competition, however, was significantly stronger for native species $(-59.6 \%)$ than for alien species (-37.5\%; Fig. 4; Table 3). There were no significant effects of intra- vs interspecific competition and of competition with alien vs competition with native species, and there were also no significant interactions of those effects with activated carbon or origin (Fig. 4; Table 3).

\section{Discussion}

We tested for allelopathic and competitive interactions between alien and native plants. In our large germination experiment, we found evidence for negative allelopathic effects of plant extracts on seed germination. This was particularly the case for extracts from the native species. Moreover, the extracts had slightly stronger negative effects on germination of the aliens than on germination of the natives. On the other hand, in our competition experiment, the natives suffered

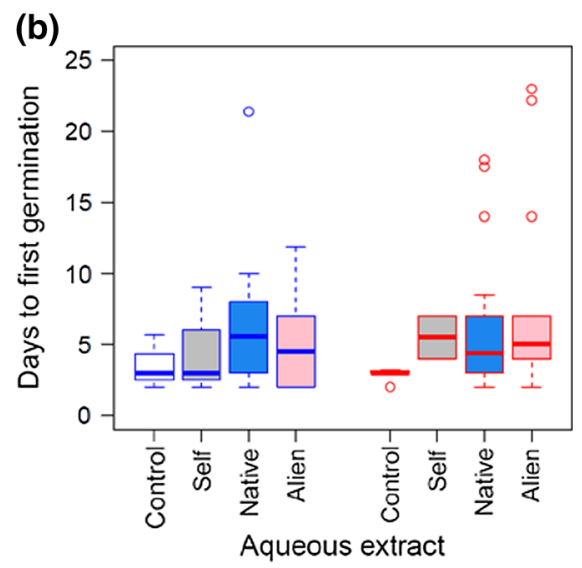

are based on the means of each combination of a test species with an aqueous extract species (or control treatment). Boxes show the interquartile range around the median (thick horizontal line), whiskers extend to $1.5 \times$ the interquartile range, and circles indicate outliers 
Table 2 Results of generalized linear mixed models testing for effects of species origin (alien, native) and extract type (control, self, alien species, native species) on the proportion of germinated seeds (binomial distribution) and number of days to first germination (Poisson distribution). The effect of extract type was decomposed into three orthogonal contrasts: treatments with plant extracts vs the water control, treatments with extracts of the same species vs those with extracts of another species, and treatments with extracts of another species that is alien vs those with extracts of another species that is native

\begin{tabular}{|c|c|c|c|c|c|}
\hline & \multirow[t]{2}{*}{$\mathrm{df}$} & \multicolumn{2}{|c|}{ Proportion of germinated seeds } & \multicolumn{2}{|c|}{ Days to first germination } \\
\hline & & $\chi^{2}$ & $P$ & $\chi^{2}$ & $P$ \\
\hline \multicolumn{6}{|l|}{ Fixed terms } \\
\hline Origin & 1 & 0.38 & 0.535 & 0.02 & 0.875 \\
\hline Extract type & 3 & 30.92 & $<0.001$ & 5.95 & 0.114 \\
\hline Extract vs control & 1 & 1.46 & 0.227 & 4.85 & 0.028 \\
\hline Self vs other & 1 & 25.46 & $<0.001$ & 0.35 & 0.552 \\
\hline Alien vs native & 1 & 4.00 & 0.045 & 0.75 & 0.387 \\
\hline Origin $\times$ Extract type & 3 & 29.68 & $<0.001$ & 32.29 & $<0.001$ \\
\hline Origin $\times$ [Extract vs control $]$ & 1 & 27.84 & $<0.001$ & 13.91 & $<0.001$ \\
\hline Origin $\times$ [Self vs other $]$ & 1 & 1.42 & 0.233 & 0.07 & 0.795 \\
\hline Origin $\times$ [Alien vs native $]$ & 1 & 0.42 & 0.519 & 18.31 & $<0.001$ \\
\hline Random terms & & \multicolumn{2}{|c|}{ Standard deviation } & \multicolumn{2}{|c|}{ Standard deviation } \\
\hline Test species & & \multicolumn{2}{|l|}{1.114} & \multicolumn{2}{|l|}{0.2683} \\
\hline Species used as source of extracts & & \multicolumn{2}{|l|}{1.341} & \multicolumn{2}{|l|}{0.6343} \\
\hline
\end{tabular}

The identities of the test species and the species used as source of the extracts were included as random factors. For the proportion of germinated seeds, $\mathrm{n}=626$, and for days to germination, $\mathrm{n}=357$. $P$-values $<0.05$ are highlighted in bold

more from competition than the alien species did. Unfortunately, as activated carbon had negative effects on all plants, both with and without competition, the role of allelopathy in the competitive interactions remains unclear. Nevertheless, our results show that both native and alien species have negative effects on each other at different life-cycle stages, but that the strength of the effects might differ between the native and alien species.

While the novel-weapons hypothesis predicts strong allelopathic effects of some aliens on natives (Callaway and Ridenour 2004), the homeland-security hypothesis posits that the reverse should also be true (Cummings et al. 2012). While we found that the aliens had negative effects on the natives and vice versa, we did not find that these native-alien effects were any stronger than the effects of natives on other natives. This suggests that differences in co-evolutionary history between the species played no major role. Another explanation could be that the alien species have been present in China for already such a long time that they and the natives have already adapted to some degree to each other's allelochemicals (Callaway et al. 2005; Lankau 2012; Huang et al. 2018; but see Oduor et al. 2020). This is not unlikely as all five alien species are widespread in China and have been present there for at least 100 years (Table 1). It could also be that in nature many allelopathic effects are indirect effects mediated by chemical inhibition of mutualistic microbes (e.g. Stinson et al. 2006) or that plant compounds are converted into more potent phytotoxic compounds by microbes (Jilani et al. 2008). By doing the germination experiment under almost sterile conditions, we excluded these possibilities in our experiment.

Although we found no evidence for the importance of co-evolutionary history in the interactions between the aliens and natives, we found that they differed in their allelopathic effects and responses. The natives had on average slightly stronger allelopathic effects, and the aliens showed stronger negative responses, in terms of germination. The latter, however, mainly reflects that the aliens had far higher germination rates than the natives in the absence of aqueous extracts, whereas the aliens and natives showed similarly low germination rates with extracts. This is in line with the 


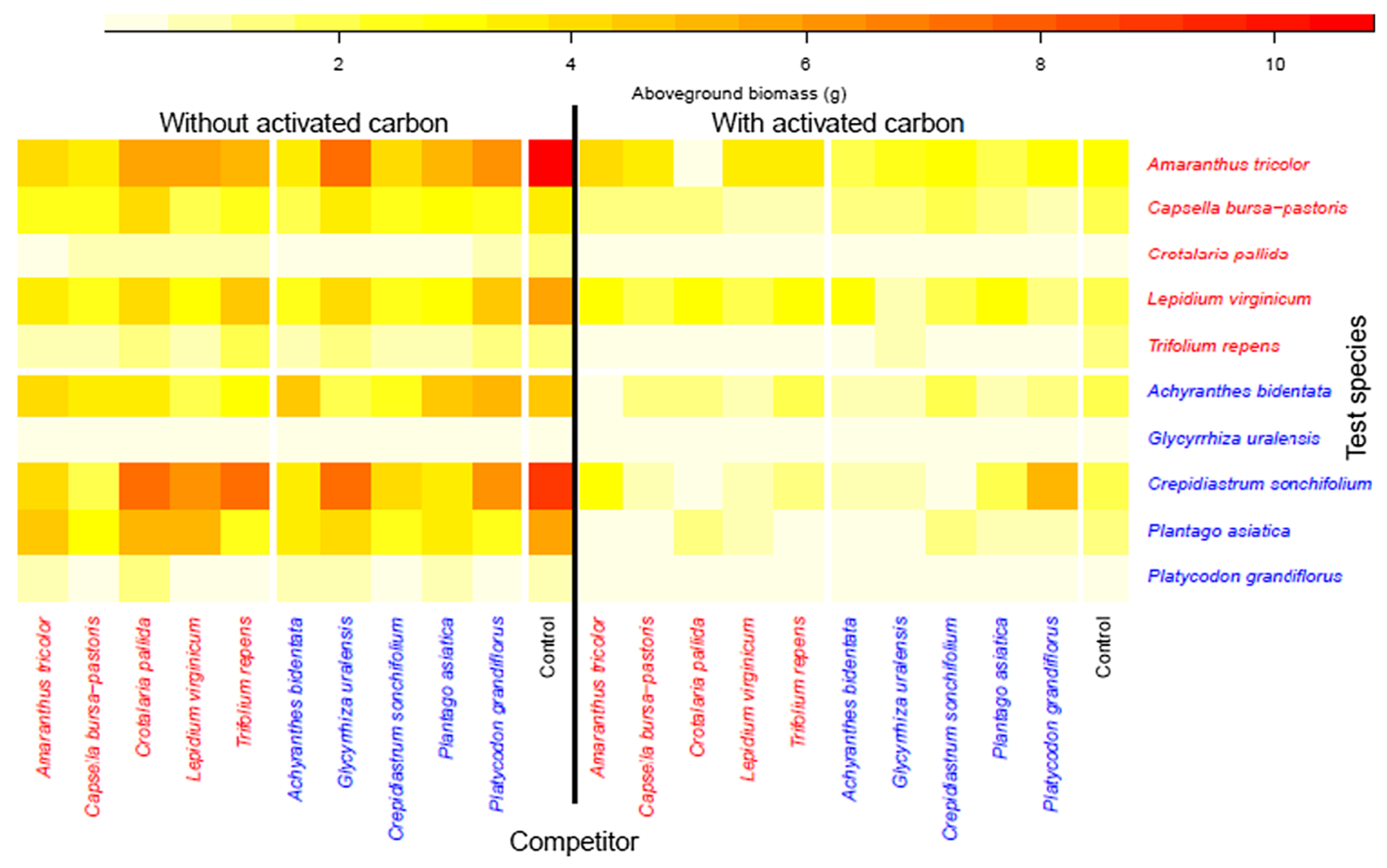

Fig. 3 Heatplot showing the mean aboveground biomass of a target species for each combination of a test species and competitor species (or control treatment without competition) in the absence or presence of activated carbon. Alien species are in red, and native species are in blue

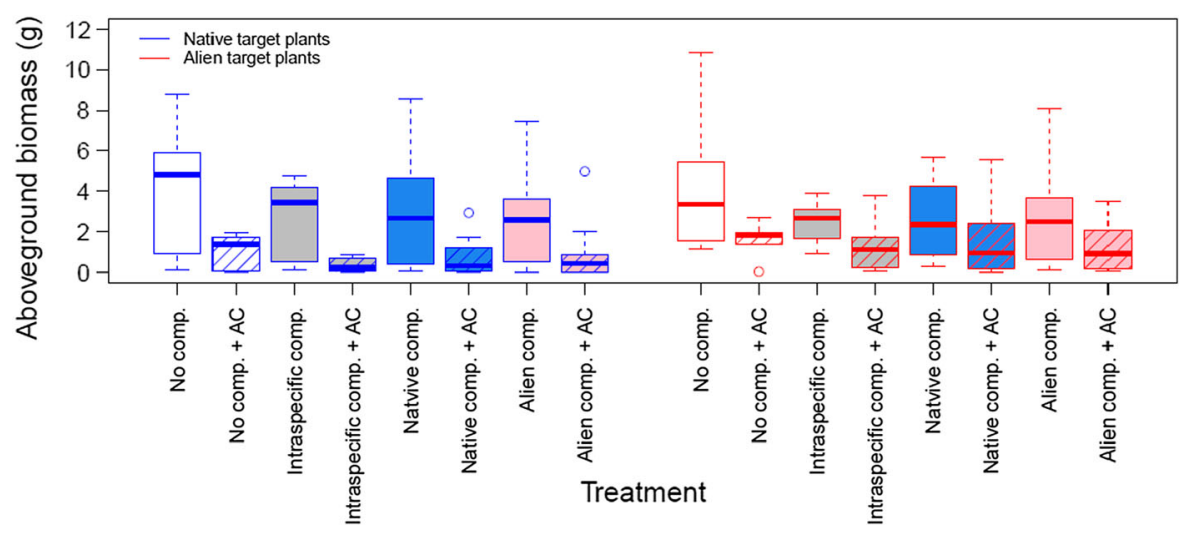

Fig. 4 Boxplots of the aboveground biomass for native target plants (blue box lines) and alien target plants (red box lines) for the treatment without competition (white filling of boxes) without and with activated carbon (hatch filling), and the treatment with intraspecific competition (grey filling) without and with activated carbon, the treatment with native competitor (light blue filling) without and with activated carbon, and treatment with alien competitor (light red filling) without and with activated carbon. The boxplots are based on the means of each combination of a target species with a competitor species (or control treatment). Boxes show the interquartile range around the median (fat horizontal line), whiskers extend to $1.5 \times$ the interquartile range, and circles indicate outliers 
Table 3 Results of generalized linear mixed models testing for effects of activated carbon (with, without), species origin (alien, native) and competition treatment (intraspecific competition, interspecific with alien species, interspecific with native species, without competition) on aboveground biomass. The effect of competition treatment was decomposed into three contrasts: with vs without competition, intra- vs interspecific competition, and competition with an alien vs with a native

\begin{tabular}{|c|c|c|c|}
\hline & \multicolumn{3}{|c|}{ Aboveground biomass } \\
\hline & df & $\chi^{2}$ & $P$ \\
\hline \multicolumn{4}{|l|}{ Fixed terms } \\
\hline Activated carbon (AC) & 1 & 258.74 & $<0.001$ \\
\hline Origin & 1 & 0.57 & 0.450 \\
\hline Competition treatment & 3 & 8.10 & 0.044 \\
\hline With vs without competition & 1 & 6.81 & 0.009 \\
\hline Intra- vs interspecific & 1 & 0.003 & 0.959 \\
\hline Alien vs native & 1 & 1.29 & 0.256 \\
\hline $\mathrm{AC} \times$ Origin & 1 & 0.48 & 0.490 \\
\hline$A C \times$ Competition treatment & 3 & 2.90 & 0.407 \\
\hline AC $\times[$ With vs without competition] & 1 & 0.29 & 0.589 \\
\hline $\mathrm{AC} \times[$ Intra- vs interspecific $]$ & 1 & 1.27 & 0.259 \\
\hline $\mathrm{AC} \times[$ Alien vs native $]$ & 1 & 1.34 & 0.248 \\
\hline Origin $\times$ Competition treatment & 3 & 6.25 & 0.100 \\
\hline Origin $\times$ [With vs without competition] & 1 & 5.61 & 0.018 \\
\hline Origin $\times$ [Intra- vs interspecific $]$ & 1 & 0.55 & 0.460 \\
\hline Origin $\times$ [Alien vs native $]$ & 1 & 0.09 & 0.763 \\
\hline$A C \times$ Origin $\times$ Competition treatment & 3 & 0.07 & 0.995 \\
\hline $\mathrm{AC} \times$ Origin $\times[$ With vs without competition $]$ & 1 & 0.07 & 0.798 \\
\hline AC $\times$ Origin $\times[$ Intra- vs interspecific $]$ & 1 & 0.008 & 0.930 \\
\hline AC $\times$ Origin $\times[$ Alien vs native $]$ & 1 & 0.0004 & 0.984 \\
\hline Random terms & \multicolumn{3}{|c|}{ Standard deviation } \\
\hline Test species & \multicolumn{3}{|c|}{$0.3919^{\dagger}$} \\
\hline Competitor species & \multicolumn{3}{|c|}{0.0239} \\
\hline Residual & \multicolumn{3}{|c|}{0.3959} \\
\hline
\end{tabular}

$\mathrm{n}=797$. The identities of the test species and of the species used as competitors were included as random factors. $P$-values $<0.05$ are highlighted in bold. ${ }^{\dagger}$ Standard deviations were allowed to differ among test species. The one shown is for A. bidentata. For the other species, this value is multiplied with 1.105 (A. tricolor), 0.695 (C. bursa-pastoris), 1.165 (C. sonchifolium), 0.561 (C. pallida), 0.377 (G. uralensis), 0.731 (L. virginicum), 1.042 (P. asiatica), 0.534 (P. grandiflorus) or 0.520 (T. repens)

idea that naturalized aliens are more opportunistic and take more advantage of beneficial conditions (Richards et al. 2006; Davidson et al. 2011; Dawson et al. 2012), in this case from allelochemical-free conditions. On the other hand, in the competition experiment, the aliens appeared to take less advantage of the competition-free conditions. Therefore, it remains unclear whether overall the aliens are more opportunistic than the aliens.

The species with low germination rates generally also took longer to germinate. However, there were a few differences in the effects of the aqueous extracts on germination rate and speed. For example, while for germination rate there was no significant interaction between the origins of the test and extract species, germination of native species was delayed most by extracts from other native species, whereas germination of alien species was delayed most by extracts from other alien species. These results are opposite to the predictions of the novel-weapons and homelandsecurity hypotheses (Callaway and Ridenour 2004; Cummings et al. 2012). Although these differences in 
germination speed did not coincide with differences in the proportion of germinated seeds, earlier or delayed seed germination can have fitness consequences. For example, earlier germination gives seedlings a size advantage over the ones that emerge later (priority effects; Gioria and Osborne 2014; Godoy et al. 2009; Wainwright et al. 2012). On the other hand, delaying germination helps to avoid competition if it allows seeds to remain dormant until more favourable conditions arise (Fenner and Thompson 2005).

Several previous studies found, just like our study, evidence for allelopathic effects of native plant species on alien species. For instance, adding leaf litter of the native legume tree Diphysa americana to soil reduced tiller survival and height growth of the invasive grass Saccharum spontaneum in Panama (Cummings et al. 2012). Similarly, adding litter of native plant species from evergreen broadleaf monsoon forests to soil decreased biomass and leaf area of the alien invader Mikania micrantha in subtropical China (Hou et al. 2011). Furthermore, the native shrub Polygonella myriophylla had negative allelopathic effects on the alien grass Paspalum notatum in Florida (Weidenhamer and Romeo 2005), and communities of native species had negative allelopathic effects on the invader Solidago canadensis in China (Adomako et al. 2019). These findings provide support for the homeland-security hypothesis. However, while these studies showed that invasive alien plants suffer from allelopathy of native plants, most of them did not test whether these effects differ from the effects on noninvasive alien or native species. In other words, it could be that the allelopathic effects observed are general allelopathic effects that do not depend on the origin of the species. An exception is a study by Mignoni et al. (2018) who found allelopathic effects of the native Sesbania virgata on the alien Leucaena leucocepahala in Brazil, but not the other way around. This shows that allelopathic effects of species on each other can be asymmetric. Ning et al. (2016), on the other hand, also found evidence for allelopathic effects of native communities on alien species in Germany, but did not find differences in the magnitude of the effects between invasive and non-invasive alien species. We also found variation in the allelopathic effects and responses among species, but we did not find that interactions between alien and native species were consistently different from interactions between native species or between alien species. More studies are needed to test whether this is a general result, and whether it depends on the degree of invasiveness of the alien species and the commonness of the native species.

Interestingly, we found that germination was most strongly inhibited if the aqueous extract was from the same species as the test seeds. In other words, we found strong evidence for auto-allelopathy (KatoNoguchi et al. 2017; Hisashi et al. 2017; Hameed et al. 2019). Particularly, if the auto-allelochemicals induce seed dormancy and do not decrease seed viability, auto-allelopathy can regulate populations over space and time to avoid severe intraspecific competition (Singh et al. 1999). Although auto-allelopathy has been found for a large number of weeds and crops in natural and agricultural ecosystems (Singh et al. 1999; Hisashi et al. 2017; Tanveer et al. 2019; Zhang and Kleunen 2019), we found that it actually exceeded hetero-allelopathy. This is surprising given that a recent meta-analysis found that the effect of allelopathy became more negative with increasing phylogenetic distance between the species (Zhang et al. 2020). This meta-analysis, however, did not distinguish explicitly between auto- and hetero-allelopathy, and testing the generality of our finding thus requires more research.

As allelopathy usually has stronger impacts on plant growth than on seed germination (Zhang et al. 2020), we also did a competition experiment. We used activated carbon as a presumed neutralizer of allelopathic compounds, as this has been successfully used in previous studies on allelopathy (Mahall and Callaway 1992; Inderjit 2003; Mangla et al. 2008; Lankau 2010). However, other studies have pointed out that activated carbon can have undesired side-effects, and that it is therefore important to also test its effects in the absence of competition (Lau et al. 2008; Weißhuhn and Prati 2009; Kabouw et al. 2010). We did this and unfortunately found that activated carbon had strong negative effects on plant growth, even when plants were grown without competition. Therefore, we are not able to infer how much of the competitive interactions between the plants were due to resource competition and how much was due to allelopathy (a form of interference competition). To gain some insights into the effects of activated carbon, we also measured several root traits on the plants in the competition-free treatment (Supplementary material), and found that activated carbon addition reduced the 
total root length as well as the root-weight ratio (Fig. S3). This shows that plants invested less biomass in roots when activated carbon was present. Furthermore, the specific root length (i.e. root length/root biomass) and the number of root tips per unit root biomass were both higher in the presence of activated carbon, indicating that activated carbon caused the roots to elongate (i.e. become thinner) and branch (Fig. S3). So, activated carbon clearly affected the plant's root system and overall plant growth, and we therefore recommend against the use of activated carbon in studies on allelopathy, unless it has been shown that it does not have side effects in the particular study system.

In conclusion, we showed that alien plants have negative competitive and allelopathic effects on native plants, and that the reverse is also true. These aliennative interactions, however, were not consistently stronger or weaker than native-native interactions or alien-alien interactions. So, we found no strong evidence that co-evolutionary history between the plant species played a major role in the strengths of their interactions. In other words, while some alien species may have novel weapons, and some natives may contribute to homeland security, we did not find general support for those hypotheses.

Acknowledgements We thank Bicheng Dong for extracting data on first records of alien species from the Chinese Virtual Herbarium. This work was supported by the Research Foundation for Advanced Talents in Taizhou University.

Author contributions MvK, JL and FH came up with the idea. $\mathrm{YL}$ and $\mathrm{MvK}$ designed the experiment. YL performed the experiment. MvK, YL and AO analysed the data. YL and MvK wrote the paper with contributions of the other authors.

Funding Open Access funding enabled and organized by Projekt DEAL. This work was supported by the Research Foundation for Advanced Talents in Taizhou University (Grant No. 0104010008).

Data availability Upon acceptance of the manuscript, the data will be made available through Figshare.

Code availability Upon acceptance of the manuscript, the $\mathrm{R}$ code will be made available through Figshare.

\section{Declarations}

Conflicts of interest None.
Open Access This article is licensed under a Creative Commons Attribution 4.0 International License, which permits use, sharing, adaptation, distribution and reproduction in any medium or format, as long as you give appropriate credit to the original author(s) and the source, provide a link to the Creative Commons licence, and indicate if changes were made. The images or other third party material in this article are included in the article's Creative Commons licence, unless indicated otherwise in a credit line to the material. If material is not included in the article's Creative Commons licence and your intended use is not permitted by statutory regulation or exceeds the permitted use, you will need to obtain permission directly from the copyright holder. To view a copy of this licence, visit http://creativecommons.org/licenses/by/4.0/.

\section{References}

Abhilasha D, Quintana N, Vivanco J, Joshi J (2008) Do allelopathic compounds in invasive Solidago canadensis s.l. restrain the native European flora? J Ecol 96:993-1001

Adomako MO, Ning L, Tang M, Du DL, van Kleunen M, Yu FH (2019) Diversity- and density-mediated allelopathic effects of resident plant communities on invasion by an exotic plant. Plant Soil 440:581-592

Baker HG (1974) The evolution of weeds. Annu Rev Ecol Syst 5:1-24

Bates D, Mächler M, Bolker BM, Sc W (2014) Package lme4: linear mixed-effects models using Eigen and S4. R package version $1.1-7$

Becerra P, Catford J, Inderjit LM, Andonian K, Aschehoug E, Montesinos D, Callaway R (2018) Inhibitory effects of Eucalyptus globulus on understorey plant growth and species richness are greater in non-native regions. Global Ecol Biogeogr 27:68-76

Callaway R, Ridenour W (2004) Novel weapons: invasive success and the evolution of increased competitive ability. Front Ecol Environ 2:436-443

Callaway R, Ridenour W, Laboski T, Weir T, Vivanco J (2005) Natural selection for resistance to the allelopathic effects of invasive plants. J Ecol 93:576-583

Christina M, Rouifed S, Puijalon S, Vallier F, Meiffren G, Bellvert F, Piola F (2015) Allelopathic effect of a native species on a major plant invader in Europe. Sci Nat 102:12

Cummings J, Parker I, Gilbert G (2012) Allelopathy: a tool for weed management in forest restoration. Plant Ecol 213:1975-1989

Davidson AM, Jennions M, Nicotra AB (2011) Do invasive species show higher phenotypic plasticity than native species and if so, is it adaptive? A meta-analysis. Ecol Lett 14:419-431

Dawson W, Fischer M, van Kleunen M (2011) The maximum relative growth rate of common UK plant species is positively associated with their global invasiveness. Global Ecol Biogeogr 20:299-306

Dawson W, Fischer M, van Kleunen M (2012) Common and rare plant species respond differently to fertilisation and 
competition, whether they are alien or native. Ecol Lett 15:873-880

Fenner M, Thompson K (2005) The ecology of seeds, 2nd edn. Cambridge University Press, Cambridge

Gioria M, Osborne B (2014) Resource competition in plant invasions: emerging patterns and research needs. Front Plant Sci 5:1-21

Godoy O, Castro-Díez P, Valladares F, Costa-Tenorio M (2009) Different flowering phenology of alien invasive species in Spain: evidence for the use of an empty temporal niche? Plant Biol 11:803-811

Golivets M, Wallin KF (2018) Neighbour tolerance, not suppression, provides competitive advantage to non-native plants. Ecol Lett 21:745-759

Gómez-Aparicio L, Canham C (2008) Neighbourhood analyses of the allelopathic effects of the invasive tree Ailanthus altissima in temperate forests. J Ecol 96:447-458

Hameed A, Shahina M, Young LS et al (2019) Bacteriostatic stimulus of meropenem on allelochemical-metabolizing Burkholderia sp. LS-044 mitigates ferulic acid autotoxicity in rice (Oryza sativa ssp.japonica cv. Tainung 71). Plant Soil 443:73-86

Hisashi KN, Keisuke N, Osamu O et al (2017) Asparagus decline: autotoxicity and autotoxic compounds in asparagus rhizomes. J Plant Physiol 213:23-29

Hou YP, Peng SL, Chen BM, Ni GY (2011) Inhibition of an invasive plant (Mikania micrantha H.B.K.) by soils of three different forests in lower subtropical China. Biol Invasions 13:381-391

Huang F, Lankau R, Peng S (2018) Coexistence via coevolution driven by reduced allelochemical effects and increased tolerance to competition between invasive and native plants. New Phytol 218:357-369

Inderjit CRM (2003) Experimental designs for the study of allelopathy. Plant Soil 256:1-11

Inderjit EH, Crocoll C, Bajpai D, Kaur R, Feng YL, Silva C, Carreón JT, Valiente-Banuet A, Gershenzon J, Callaway RM (2011) Volatile chemicals from leaf litter are associated with invasiveness of a neotropical weed in Asia. Ecology 92:316-324

Irimia R, Lopes S, Sotes G, Cavieres L, Eren Ö, Lortie C, French K, Hierro J, Rosche C, Callaway R, Melo T, Montesinos D (2019) Biogeographic differences in the allelopathy of leaf surface extracts of an invasive weed. Biol Invasions 21:3151-3168

Jilani G, Mahmood S, Chaudhry AN, Hassan I, Akram M (2008) Allelochemicals: sources, toxicity and microbial transformation in soil-a review. Ann Microbiol 58:351-357

Kabouw P, Nab M, van Dam NM (2010) Activated carbon addition affects substrate $\mathrm{pH}$ and germination of six plant species. Soil Biol Biochem 42:1165-1167

Kato-Noguchi H, Nakamura K, Ohno O, Suenaga K, Okuda N (2017) Asparagus decline: autotoxicity and autotoxic compounds in asparagus rhizomes. J Plant Physiol 213:23-29

Kuebbing SE, Nuñez MA (2016) Invasive non-native plants have a greater effect on neighbouring natives than other non-natives. Nat Plants 2:16134

Lachaise T, Bergmann J, Rillig MC, van Kleunen M (2021) Below- and aboveground traits explain local abundance, and regional, continental and global occurrence frequencies of grassland plants. Oikos 130:110-120

Lankau R (2010) Soil microbial communities alter allelopathic competition between Alliaria petiolata and a native species. Biol Invasions 12:2059-2068

Lankau RA (2012) Coevolution between invasive and native plants driven by chemical competition and soil biota. PNAS 109:11240-11245

Lau JA, Puliafico KP, Kopshever JA, Steltzer H, Jarvis EP, Schwarzländer M, Strauss SY, Hufbauer RA (2008) Inference of allelopathy is complicated by effects of activated carbon on plant trowth. New Phytol 178:412-423

Li J, Jin Z (2010) Potential allelopathic effects of Mikania micrantha on the seed germination and seedling growth of Coix lacryma-jobi. Weed Biol Manage 10:194-201

Mahall B, Callaway R (1992) Root communication mechanisms and intracommunity distributions of two Mojave Desert shrubs. Ecology 73:2145-2151

Mangla S, Callaway IM, Callaway RM (2008) Exotic invasive plant accumulates native soil pathogens which inhibit native plants. J Ecol 96:58-67

Mignoni DS, Simões K, Braga MR (2018) Potential allelopathic effects of the tropical legume Sesbania virgata on the alien Leucaena leucocephala related to seed carbohydrate metabolism. Biol Invasions 20:165-180

Ning L, Yu FH, van Kleunen M (2016) Allelopathy of a native grassland community as a potential mechanism of resistance against invasion by introduced plants. Biol Invasions 18:3481-3493

Oduor A, van Kleunen M, Stift M (2020) Allelopathic effects of native and invasive Brassica nigra do not support the novel-weapons hypothesis. Am J Bot 107:1-8

Ohdan H, Daimon H, Mimoto H (1995) Evaluation of allelopathy in Crotalaria by using a seed pack growth pouch. Jpn J Crop Sci 64:644-649

Pinheiro J, Bates D, DebRoy S, Sarkar D, R Core Team (2015) nlme: linear and nonlinear mixed effects models. R package version 3.1-119. http://CRAN.R-project.org/package= nlme

POWO (2019) Plants of the world online. Facilitated by the Royal Botanic Gardens, Kew. Published on the Internet; http://www.plantsoftheworldonline.org/. Accessed 11 Jan 2021

Prati D, Bossdorf O (2004) Allelopathic inhibition of germination by Alliaria petiolata (Brassicaceae). Am J Bot 91:285-288

Pyšek P, Richardson DM (2007) Traits associated with invasiveness in alien plants: where do we stand? In: Nentwig W (ed) Biol invasions. Springer, Berlin

Rabotnov TA (1982) Importance of the evolutionary approach to the study of allelopathy. Ekologia 3:5-8 (Translated from Russian)

R Core Team (2019) R: A Language and Environment for Statistical Computing, 3.6.1 edn. R Foundation for Statistical Computing, Vienna, Austria

Richards CL, Bossdorf O, Muth NZ, Gurevitch J, Pigliucci M (2006) Jack of all trades, master of some? On the role of phenotypic plasticity in plant invasions. Ecol Lett 9:981-993 
Richardson DM, Pyšek P, Rejmánek M, Barbour MG, Panetta FD, West CJ (2000) Naturalization and invasion of alien plants: concepts and definitions. Divers Distrib 6:93-107

Ridenour WM, Callaway RM (2001) The relative importance of allelopathy in interference: the effects of an invasive weed on a native bunchgrass. Oecologia 126:444-450

Sakai AK, Allendorf FW, Holt JS et al (2001) The population biology of invasive species. Annu Rev Ecol Syst 32:305-332

Schaffner U, Steinbach S, Sun Y, Skjøth CA, de Weger LA, Lommen ST, Augustinus BA, Bonini M, Karrer G, Šikoparija B, Thibaudon M, Müller-Schärer H (2020) Biological weed control to relieve millions from Ambrosia allergies in Europe. Nat Commun 11:1745

Singh HP, Batish DR, Kohli RK (1999) Autotoxicity: concept, organisms, and ecological significance. Crit Rev Plant Sci 18:757-772

Stinson KA, Campbell SA, Powell JR et al (2006) Invasive plant suppresses the growth of native tree seedlins by disrupting belowground mutualisms. PLoS Biol 4:e140

Tanveer A, Jabbar MK, Kahliq A, Matloob A, Abbas RN, Javaid MM (2019) Allelopathic effects of the aqueous an organic fractions of Euphorbia dracunculoides LAM. on germination and seedling growth of chickpea and wheat. Chilean JAR 72:495-501

Thorpe AS, Thelen GC, Diaconu A, Callaway RM (2009) Root exudate is allelopathic in invaded community but not in native community: field evidence for the novel weapons hypothesis. J Ecol 97:641-645

van Kleunen M, Weber E, Fischer M (2010) A meta-analysis of trait differences between invasive and non-invasive plant species. Ecol Lett 13:235-245

van Kleunen M, Dawson W, Essl F et al (2015) Global exchange and accumulation of non-native plants. Nature 525:100-103

van Kleunen M, Bossdorf O, Dawson W (2018a) The ecology and evolution of alien plants. Ann Rev Ecol, Evol Syst 49:25-47

van Kleunen M, Essl F, Pergl J et al (2018b) The changing role of ornamental horticulture in alien plant invasions. Biol Rev 93:1421-1437

Vilà M, Espinar JL, Hejda M, Hulme PE, Jarošík V, Maron JL, Pergl J, Schaffner U, Sun Y, Pyšek P (2011) Ecological impacts of invasive alien plants: a meta-analysis of their effects on species, communities and ecosystems. Ecol Lett $14: 702-708$
Wainwright CE, Wolkovich EM, Cleland EE (2012) Seasonal priority effects: implications for invasion and restoration in a semi-arid system. J Appl Ecol 49:234-241

Wang R, Feng Z, Liang X, Xu W, Su Y, Song Y, Zeng R (2012) Comparative allelopathic and competitive abilities of 3-native forage legumes and the invasive weed Bidens pilosa L. Allelopathy J 29:297-306

Weidenhamer JD, Romeo JT (2005) Allelopathy as a mechanism for resisting invasion: the case of Polygonella myriophylla. In: Inderjit S (ed) Invasive plants: ecological and agricultural aspects. Birkhäuser, Basel

Weißhuhn K, Prati D (2009) Activated carbon may have undesired side effects for testing allelopathy in invasive plants. Basic Appl Ecol 10:500-507

Yan XL, Liu QR, Shou HY et al (2014) The categorization and analysis on the geographic distribution patterns of Chinese alien invasive plants. Biodiv Sci 22:667-676

Yan XL, Wang ZH, Ma JS (2019) The checklist of the naturalized plants in China. Shanghai scientific and technical publishers, Shanghai

Yan Z-Q, Tan J, Guo K, Yao L-G (2020) Phytotoxic mechanism of allelochemical liquiritin on root growth of lettuce seedlings. Plant Signal Behav 15:e1795581

Yu T, Meng HW, Wen YB, Cheng ZH (2013) Allelopathy of Trifolium repens L. exudates on five turfgrass types. Acta Agrestia Sin 21:729-736

Zhang SY, Ding BY (1993) Zhejiang flora. Zhejiang Science and Technology Publishing House

Zhang Z, van Kleunen M (2019) Common alien plants are more competitive than rare natives but not than common natives. Ecol Lett 22:1378-1386

Zhang Z, Fan J, Wu J, Zhang L, Wang J, Zhang B, Wang-Pruski $G$ (2020) Alleviating effect of silicon on melon seed germination under autotoxicity stress. Ecotoxicol Environ Saf 188:109901

Zhao Y, Tang NK, Gao XY (2019) Study on allelopathic effects of Crotalaria pallida Ait. extracts. Hortic Seed 39:1-4

Zuur A, Ieno EN, Walker N, Saveliev AA, Smith GM (2009) Mixed effects models and extensions in ecology with R. Springer, New York

Publisher's Note Springer Nature remains neutral with regard to jurisdictional claims in published maps and institutional affiliations. 